\title{
A BUSCA PELA ESCOLA DIFERENCIADA E $O$ I MOVIMENTO PELA EDUCAÇÃO ESCOLAR INDÍGENA APINAJÉ
}

\author{
GOMES, Dhiogo Rezende \\ Universidade Federal do Tocantins (UFT)
}

\section{RESUMO}

Este texto apresenta-se como fragmento adaptado de uma pesquisa que culminou na dissertação de mestrado "MĒ IXUJARĒNH - Ausência, presença e busca: o ensino de história na Escola Indígena Tekator do povo Panhĩ-Apinajé", concluída em 2016. Aponta-se para registro e reflexão, aqui, parte do processo de busca do povo Apinajé por uma escola indígena que se enquadre como diferenciada e atrelada à construção de um projeto de educação escolar protagonizado por atores indígenas, em que os Apinajé vêm tomando posição. Uma participação ativa e política que busca a escola intercultural, diferenciada e específica nos modos de produção e transmissão dos conhecimentos tradicionais e escolarizados. Um movimento pela educação escolar Apinajé visualizado na organização do primeiro evento político organizado e executado pela comunidade escolar da Tekator, que vem retomando nos últimos anos pautas pertinentes neste contexto, em reuniões importantes, tendo a escola Apinajé e diferenciada como objetivo.

Palavras-chave: Educação escolar indígena. Povo Apinajé. Escola indígena diferenciada.

\section{ABSTRACT}

This text is the result of a research presented as an adapted fragment of the master's thesis: MĒ IXUJARĒNH - Absence, presence and search: the teaching of history in the Tekator Indigenous School of the Panhĩ people Apinajé, completed in 2016. It is pointed out part of the Process of search of the Apinajé people for an indigenous school that fits as differentiated and linked in the construction of a school education project carried out by indigenous actors, whose Apinajé has been taking position. An active and political participation that seeks the intercultural school, differentiated and specific in the modes of production and transmission of traditional 
and scholarized knowledge. A movement for school education Apinajé visualized in the organization of the first political event organized and executed by the school community of Tekator that has been resuming in recent years relevant guidelines in this context in important meetings having the Apinajé school and differentiated as an objective.

Key words: Indigenous school education. Apinajé people. Differentiated indigenous school.

\section{INTRODUÇÃO}

Essa busca pela escola diferenciada, que não se pode precisar no tempo (a partir de tal data), mas se insere no contexto desse povo, em contato com a "escola invasora", não termina, é cotidiana à "descolonização e à domesticação escolar", e não se inicia no primeiro Movimento pela Educação Escolar Apinajé em 2016.

A luta pela educação escolar indígena Apinajé se fez um pouco mais tardia, mas ainda contemporânea e implicada na sempre existente luta pela terra e defesa do território. Essa presença indígena (do Movimento) recente na cidade de Tocantinópolis, município do norte do Estado do Tocantins, apoia-se na memória dos esforços históricos da demarcação da Terra Apinajé (1985), à revelia da sociedade nacional e regional, representada por fazendeiros, políticos, órgãos de governos e boa parte dos moradores dos municípios abrangentes da área demarcada.

Assim como a terra necessitou de um "Mutirão Guerreiro", na união dos Apinajé e outros irmãos de outras etnias de várias regiões do Brasil (CARELLI, 1985), iniciou-se oficialmente a demarcação de outro lugar caro a este povo, o da escola indígena diferenciada. Puxado pela Escola Indígena Tekator, esse primeiro movimento em 2016 pode ser o anúncio de uma primavera pela educação, trazendo um dia a escola almejada, assim como aconteceu com o território demarcado.

Nos últimos anos, há uma emergência ativa dos Apinajé contra ameaças de desmatamento, de roubo de madeira, de invasões, reivindicações por energia e manutenção das vicinais entre as

1 Movimento realizado em 17 de março de 2016, na cidade de Tocantinópolis-TO. Primeira manifestação pública organizada com pleno protagonismo Apinajé, reivindicando uma escola diferenciada de acordo com as expectativas indígenas. 
aldeias, até de asfaltamento da rodovia que corta o território (TO 126). Para estes fins, utilizaram estratégias de bloqueios de estradas usadas pelos não-indígenas. Mas só pela educação, os Apinajé venceram os receios das animosidades e preconceitos dos "brancos" e foram literalmente "pintados para guerra" até a cidade, cobrar das autoridades nos órgãos competentes, usando a estratégia do microfone, do argumento em português, em parte adquirido na própria escolarização.

A Escola Indígena Apinajé, mesmo não sendo, ainda, a que eles querem, diferenciada, já serve como plataforma de inúmeras ações e atividades que vão despertando as comunidades, dando vistas da realidade indígena diante dos descompassos da educação e de políticas públicas a este povo destinadas. Trata-se da escola se tornando instrumento, sendo usada como meio para fins coletivos. A Tekator revela seu potencial em reuniões no seu pátio, como as que antecederam o pioneiro movimento pela educação indígena na cidade.

\section{Os Pēp: a guarda guerreira pela educação escolar indígena Apinajé}

Na reunião que serviu de preparatório para o movimento pela educação, houve a adaptação de um ritual, a "formação de guerreiros", os $P \bar{e} p^{3}$. Estes foram selecionados entre os estudantes como "seguranças" para a manifestação na cidade, proteção da comunidade nas ruas fora da terra indígena, grupo que permaneceu vigilante na disciplina escolar, evitando brigas, entrada de estudantes com bebidas alcoólicas, desrespeito aos professores e demais colegas. Empossados na frente da comunidade pelo Diretor escolar nesta reunião, estavam eles. como primeira coluna no dia do movimento, pintados de vermelho e preto (urucum e jenipapo), empunhando

2 Registramos esses "guerreiros em ação". Fizemos um vídeo com o título: I Movimento pela Educação Escolar Apinajé, o qual é possível acessar no endereço eletrônico: https://www.youtube.com/watch?v=VT1ssQ8JRig

3 Trata-se do antigo ritual Pepkahàk (Grandes Guerreiros). Consistia em meses, anos de formação. Jovens iniciavam uma jornada de conhecimentos da vida Apinajé, orientados por adultos experientes. Ficavam grandes períodos na floresta sem ver a família. Regressavam e o ritual tinha continuidade na comunidade. Ver Nimuendajú (1983) cap. VIII Classes de idade, IX Iniciações dos novos guerreiros. 
bordunas ${ }^{4}$. Um antigo ritual, significativo da educação tradicional na formação dos jovens, na preparação de guerreiros para a vida adulta Apinajé, estava sendo parcialmente revivido intermediado na educação escolar.

$\mathrm{Na}$ reunião, ${ }^{5}$ a luta pela demarcação da Terra Indígena Apinajé em 1985, foi lembrada nas falas, e, a partir desta retomada histórica, explorou-se o zelo pelo território, a vigilância necessária às ameaças sempre presentes, os prejuízos e ataques políticos governamentais e de empreendimentos econômicos a soberania e aos direitos dos povos indígenas, no nível local, regional e nacional. Nessa perspectiva, a escola indígena Tekator vem se colocando como um espaço de discussão política entre as comunidades das aldeias que tem a aldeia Mariazinha como sede.

A exemplo de debates organizados pelos estudantes sobre as últimas eleições, municipais, estadual e federal (2012 e 2014), a escola e sua comunidade estão no centro dos últimos movimentos ${ }^{6}$ (2014, 2015 e 2016) em que os Apinajé protestaram por melhorias nas condições das estradas, vias de acesso as escolas das aldeias. A Escola Indígena Tekator, mesmo ainda não ideal e diferenciada, vem sendo usada instrumentalmente pelos Apinajé. A relação escola, terra, estrada, direitos, fica cada vez mais visível interna e externamente.

Os Apinajé têm entidades, grupos e membros da sociedade civil que os auxiliam com conhecimentos acadêmicos nesta busca e "domesticação da escola". São o Laboratório de Línguas Indígenas (LALI-UnB), o Núcleo de Estudo e Pesquisa com Povos Indígenas (NEPPI) e o Núcleo de Estudos e Assuntos Indígenas (NEAI). Estes dois últimos fazem parte da Universidade Federal do Tocantins, contando

4 Arma feita de madeira trabalhada, geralmente pesada, uma espécie de bastão.

5 Dia 10 de março. No pátio da Escola Indígena Tekator. Das 18:30 às 22:00, falas de professores, lideranças e estudantes sobre a paralização das aulas e a organização das manifestações que se realizaram na semana seguinte, no dia 17 de março de 2016.

6 Ver as matérias do portal de notícias de Tocantinópolis e região, o Tocnoticias: A Vez dos Apinajés (2014). Endereço: http://www.tocnoticias.com. br/ler_noticia2014.php?idnoticia=5273; Por Melhorias nas Estradas das aldeias, Indígenas Apinajé Bloqueiam as Rodovias TO-126 e TO-210 em Tocantinópolis (2015). Endereço: http://www.tocnoticias.com.br/ler_noticia2014. php?idnoticia $=9273$. 
com professores, pesquisadores, graduandos na elaboração e execução de projetos educacionais e na formação de estudantes indígenas.

Recentemente, as escolas Apinajé vêm recebendo apoio para formação continuada dos professores indígenas, com o Saberes Indígenas na Escola, Ação mantida com recursos do Fundo Nacional de Desenvolvimento da Educação (FNDE).

Acontece também um evento importante para a educação dos povos Timbira, de que os Apinajé fazem parte. Trata-se do 'Seminário Temático Timbira', originado em 2005. Neste evento, trocam-se experiências de estudantes indígenas e não-indígenas, pesquisadores de universidades e instituições nacionais e internacionais, participantes e realizadores.

No VI Seminário Temático Timbira: educações e conhecimentos ${ }^{7}$, um dos trabalhos registrados nos anaisé de um professor da Escola Indígena Tekator, intitulado Alfabetização imagética e sua contextualização. Neste trabalho, Júlio Kamêr Ribeiro Apinajé defende o processo de alfabetização a partir da concepção de rituais tradicionais, como saberes que passam um mundo de sentidos e significados, onde só depois podem ser relacionados com as letras, conhecendo-se primeiro as imagens para concebê-las na escrita.

Sobre esse processo recente de contribuição cada vez mais requisitada de profissionais técnicos e acadêmicos como assessores (não-índios) e assessorados (índios), vale a reflexão proposta pelo antropólogo Gersem dos Santos Luciano (Baniwa). Sobre essa participação "qualificada e desinteressada de "brancos" às causas indígenas, ele diz que

Uma assessoria tanto pode contribuir pelo retardamento ou impedimento da caminhada, como pode também contribuir maravilhosamente para encontrar caminhos mais viáveis e antecipar as conquistas. Sem dúvida, a assessoria é muito importante e valiosa, mas precisa ser suficientemente boa. Não é de menos que existem assessorias aos índios que estão ajudando a destruir essas sociedades

7 Realizaram esse evento: FAPEMA/WYTY CATÉ/TIMBIRA FOUDATION/ PPGCSOC (UFMA)/NEAI (UFT)/CTEPPH/CTI/GRUPO DE PESQUISA ESTADO MULTICULTURAL E POLÍTICAS PÚBLICAS (UFMA)/CAMPI: SÃO LUÍS, SÃO BERNARDO E GRAJAÚ (UFMA). Este evento aconteceu na cidade de Carolina-MA, entre os dias 15 e 17 de dezembro de 2015. 
e impedindo sua organização e fortalecimento. É importante considerar que não existe assessoria passiva. Ou é favorável ou é desfavorável às sociedades indígenas. O curioso, ainda, é que na prática da luta indígena o assessor (qualquer que seja) ganha mais poder de argumentação dentro das comunidades indígenas do que o próprio líder tradicional (talvez pelo sentimento de inferioridade...) (LUCIANO, 1991 apud FERREIRA, 2001, p.110).

O antropólogo indígena trata "qualificado" como sendo o assessor que tenha conhecimento aprofundado e crítico advindo da sua formação profissional e com este poder fazer uma eficiente mediação entre os mundos indígena e não-indígena, partindo sempre da realidade presente no primeiro. Sendo então "desinteressada" a assessoria que fica alheia à essa dinâmica, agindo no fluxo dos interesses do(s) outro(s), escapando então o seu próprio, que deve ser pautado na sua função de assessoria com os pés firmes nas necessidades reais dos povos com que ele trabalha.

Ou seja, é necessária uma intensa relação, onde indígenas e não-indígenas se encontrem a partir de uma mesma realidade como plataforma de interesses, sendo uma troca, na verdade, entre mundos diferentes, partindo do mundo indígena, o qual pertence à escola, não sucumbindo à cultura indígena em nome de egocentrismos e hierarquizações. É neste processo de interação e troca que requer participação, doação, negociação de todos os envolvidos, que os Apinajé se encontram na construção de sua escola.

A Escola Indígena Tekator apresenta-se atualmente mais como "diferente" do que diferenciada. Diferente para nãoindígenas, por ser "escola de índios", que, diante dos contatos com a sociedade envolvente e os bens de consumo que ela proporciona, os membros ainda falam a língua materna, tem "cara de índio" e mantém ou readaptam a bem ou mal da escolarização, alguns rituais e manifestações tradicionais. Diferente mesmo para os próprios indígenas Apinajé, que ainda não a reconhecem como uma escola integralmente diferenciada, distante das suas aspirações.

Bilíngue e intercultural, por ter no currículo a disciplina de português e outras com conhecimentos da sociedade nacional, além da língua materna e saberes tradicionais, comunitária por estar inserida no centro das comunidades, que têm o espaço escolar como área indígena, assim como os recursos de que a mesma dispõe. 
Contudo, a Escola Indígena Tekator ainda não é diferenciada, por tudo isto ainda ser apenas "diferente", não bastando apenas o "ser por ter" (ter no currículo, na legislação), mas faltando o "ser por ser" (na prática cultural de uma pedagogia que possa ser indígena) na visão da comunidade, tornando-se assim uma escola Apinajé.

Sendo a escola uma zona, ao mesmo tempo de fronteira e contato com a sociedade envolvente, pelo destaque que o mundo externo impõe à tradição, com predominâncias de fundamentos pedagógicos ocidentais, ela se inscreve em contraste, em oposição a "ideais escolares" externos, carregando a marca de "diferente" das escolas regulares da cidade de Tocantinópolis. Cidade que conta com escolas tradicionais e religiosas e outros centros de ensino da rede estadual, unidades que recebiam $\left(\right.$ recebem $^{8}$ ) estudantes indígenas, antes e mesmo depois, das escolas indígenas pertencerem ao sistema estadual a partir de $1995^{9}$, oferecendo continuidades do ensino fundamental e médio, a exemplo do professor de Cultura $e$ Diversidade Indígena, Francisco Apinajé, que estudou fora das aldeias.

A escola da cidade, um referencial que se impõe, diferença produzida na relação de poder com o exterior. A Escola Indígena Tekator segue com professores indígenas e não-indígenas que desenvolvem, no piso das salas de aulas, um cotidiano escolar pulsante, incorporando culturalmente a vida da comunidade, que

8 Em 2014, quando professor do Colégio Dom Orione, uma instituição de ensino tradicional, católica, conveniada. A Secretaria Estadual de Educação do Tocantins guarda ainda o status de colégio da elite, apoiado no passado, quando Tocantinópolis era uma das cidades mais importantes da região de Tocantínia, sendo o Dom Orione frequentado por membros das elites regionais. Neste ano, nas turmas em que eu lecionava História, havia uma menina Apinajé, a única ao menos neste ano letivo. Estava no $1^{\circ}$ ano do ensino médio. Não tão frequente, muito tímida, poucos amigos, ficou reprovada em quase todas as disciplinas, me lembro que não gostava que na chamada proferisse o seu sobrenome "Apinajé". Na última vez em que a vi, perguntei onde ela estava estudando, disse que em outra escola pública da cidade, onde ela e outros estudantes (não-indígenas) julgam, que diferentemente do Dom Orione, é "mais fácil de passar".

9 Em "Escolas Apinayé: uma retrospectiva histórica", são abordados as Leis e os decretos de criação e funcionamento das escolas indígenas Apinajé sob responsabilidade da SEDUC-TO (SOTERO APINAYÉ; ALBUQUERQUE, 2012). 
de alguma forma vai conduzindo a escola para um lugar este que pretende ser mais indígena.

Certa vez, sobre a situação da escola em sua forma de educação, o diretor da Tekator, Emílio Dias, disse que: "A escola não está $100 \%$ ainda de ensinamento do conhecimento da cultura indígena $[. .$.$] está avançando mais, melhorando mais, estamos$ pensando numa forma de nossa cultura, que ela seja reconhecida dentro da escola [...]". Essa consciência da escola presente faz os povos indígenas pensarem no por vir, como um professor Tukano, Sebastião Duarte assim o fez, em 1996, falando para mais de 100 professores indígenas, numa reunião no Estado do Amazonas. Se referindo à escola nacional, voltada para cultura ocidental, disse que para os índios, "A escola indígena que queremos tem que ser da mesma forma, tem que estar dentro da nossa cultura. A escola que temos hoje não dá para o nosso futuro, porque ela não tem projeto de futuro" (GRUPIONI, 2008, p. 31).

Uma escola na intersecção, entre ser diferenciada, mas ser diferente, "ser igual à dos brancos" (estrutura) pelo querer indígena, com propostas e práticas curriculares ocidentais e homogêneas, pelo querer dos não-indígenas gestores do Estado. Sendo indígena para uns, sendo "de índios" para outros, uma escola entre mundos, sendo história pelo seu passado, pelo fazer no presente, dentro de um contexto, de um lugar, com vozes, intencionalidades, agências, resistências, querendo e procurando caminhos que levem a uma escola diferenciada no futuro, a deles, dos Apinajé.

A Escola Indígena Tekator e os Apinajé vêm vivendo um "despertar educacional", no mesmo ano do seu primeiro Movimento pela Educação Escolar, público para indígenas e não-índios, nas ruas de Tocantinópolis, que assistiu a um povo que, além de estradas, reivindicava educação de qualidade. Na volta dessa manifestação, na semana seguinte, os jovens " $P \bar{e} p$ ", adaptando-se um antigo ritual de formação de guerreiros para uma "Guarda Indígena" escolar e comunitária. Montaram barreira no caminho da escola, vistoriando os passantes e proibindo a entrada de bebidas alcoólicas em terras indígenas. 
Figura 1 - Barreira Pēp na TO-126, antes da entrada da aldeia Mariazinha e outras aldeias na T. I. Apinajé. Maio de 2016.

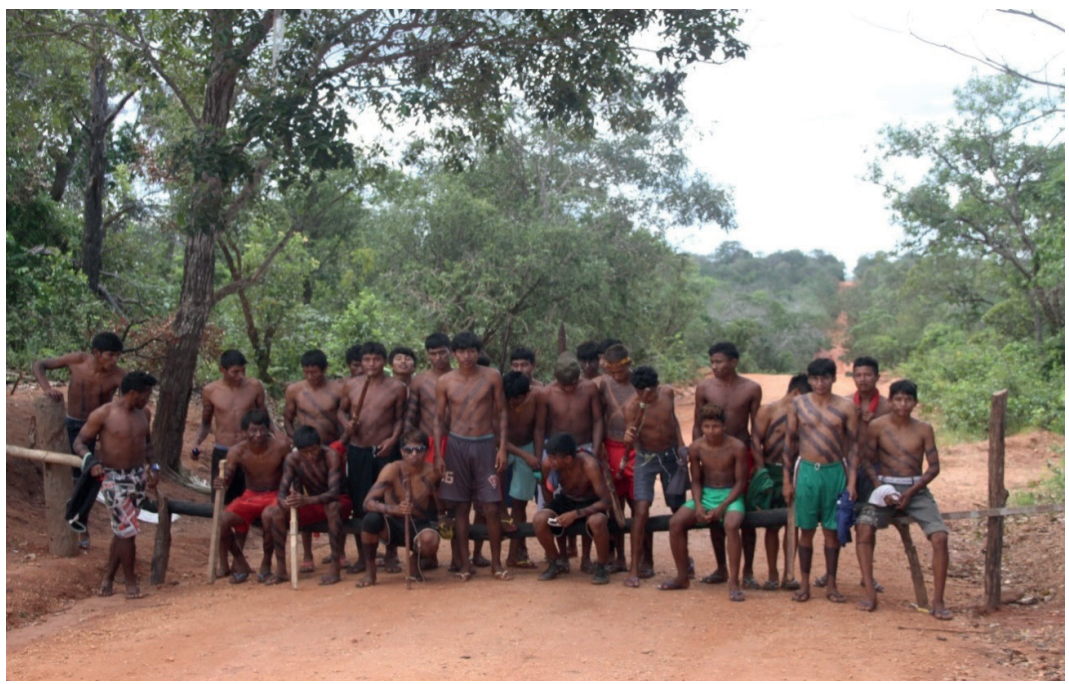

Fonte: Acervo pessoal do autor.

\section{A E.I Tekator retoma seu projeto político pedagógico}

Na semana em que houve a retomada do Projeto Político Pedagógico (PPP) numa reunião que contou com a participação dos docentes, estudantes e membros da comunidade, iniciado pelos professores e equipe diretiva entre 2005 e 2009, paralisado ou desandado por motivos de ordem burocrática e técnica. Estranhamos o tempo de projeto emperrado, mas, quando se trata de tempo entre os povos indígenas, difícil precisar o sentido de muito ou pouco tempo ${ }^{10}$. Contudo, observamos que a retomada é muito significativa, visto que tal projeto requer ampla participação da comunidade, significando mais um momento de visibilidade para a educação escolar indígena perante o próprio povo Apinajé.

Projeto que foi explicado, lido na reunião, em português e

10 Acompanhamos algumas reuniões no pátio da E. I. Tekator. Sempre duravam muito tempo, quando as lideranças, anciãos estão presentes, é seguro que praticamente todos usem a palavra. Já ouvimos falar de reuniões políticas entre os Apinajé que duraram dias. 
Apinajé, dada a importância da construção coletiva, ainda mais numa escola que busca caminhos para ser indígena, o quanto é essencial a participação da comunidade, as percepções, as vozes que viram escrita neste projeto. Um dos participantes, um ancião que vivenciou o processo de escolarização Apinajé, quase no final da tarde, da reunião iniciada pela manhã, foi perguntado, pela coordenadora pedagógica kupe, sobre o que achava, se tinha que mudar algo do que estava sendo exposto como marco orientador da política e da prática da escola Tekator, para inserir no PPP. Naquele momento, a sua resposta simples, vimos como simbólica do atual momento da educação escolar deste povo. Seu Valdeci Dias Apinajé, que é pai do diretor escolar, disse suscintamente: "Está no rumo"11!

Sobre os desafios de uma política para educação escolar indígena, o debate encontra-se enviesado. Ladeira (2004, p. 143) falou algo que ainda nos é pertinente, que "o cerne da discussão oscila entre a escolarização em si do estudante indígena enquanto indivíduo/cidadão, e aquela educação escolar voltada para o projeto político de um povo, diferente daquele da sociedade nacional".

A escola se apresenta como algo a ser lido, compreendido pelos povos indígenas. Diante dos vários momentos que acompanhamos na pesquisa de campo, a Tekator foi centro de discussões políticas frente às velhas relações de embate e negociações com a sociedade nacional representada pelo Estado. Os Apinajé mostram-se contra o Estado, no sentido de Pierre Clastres (2012), por sua sociedade se organizar politicamente não na ausência, mas contra a forma de estado ocidental que se impõe, na legislação educacional, na gerência da escola indígena. Paradoxalmente, os Apinajé são a favor da escola para inclusive, diante dessa busca, encontrar uma escola diferenciada, a qual seja um instrumento indígena contra o Estado.

Com relação a esse projeto de escola indígena Apinajé diferenciada, fora do currículo estrito para educação indígena prescrito no Estado do Tocantins, na prática escolar Apinajé, há resistências e problematizações da concepção curricular atrelada ao multiculturalismo, dando os contornos do que vem sendo a Escola Indígena Tekator. Este multiculturalismo visto como inclinado

11 A expressão "Está no rumo" pode ser também interpretada como uma forma de não se comprometer do Seu Valdeci Dias Apinajé. Mas durante a convivência com os professores, estudantes e a comunidade da aldeia Mariazinha na pesquisa, a importância da palavra deste ancião, um dos mais presentes na vida escolar da Tekator e política do seu povo, sendo um membro destacado e importante, ao nosso ver, não seria o caso dele evitar comprometimentos em sua fala nessa ocasião. Antes dessa resposta, na reunião, o ancião havia falado muito sobre assuntos pertinentes ao PPP, só que na língua materna. 
para um senso científico hegemônico que secundariza ou se faz eixo central diante de outras formas de conhecimentos tidos como tradicionais (SILVA, 2014). O paradigma da interculturalidade, no lugar do multiculturalismo de uma cultura dominante que aceita e apenas tolera as culturas e os conhecimentos tidos como periféricos e diferentes, vem ganhando força nos círculos acadêmicos, sendo passivo de alcance para indígenas em contato com o ensino superior, em ensino, pesquisa e extensão.

Interculturalidade concebida a partir de outras abordagens como na "epistemologia do Sul" (SANTOS; MENESES, 2009), com propostas e vistas educacionais que rompam com as colonialidades rumo à descolonização (ou na perspectiva "decolonial"). É neste caminho acadêmico de crítica à própria academia e à histórica construção do conhecimento científico ocidental, que uma escola Apinajé diferenciada pode se encontrar no futuro, agregando-se aos passos já dados pelos povos indígenas em suas experiências intraculturais e interculturais autonomamente.

Figura 2 - Sr. Valdeci participando da reunião para a elaboração do PPP da Escola Indígena Tekator (Dia 24/03/2016)

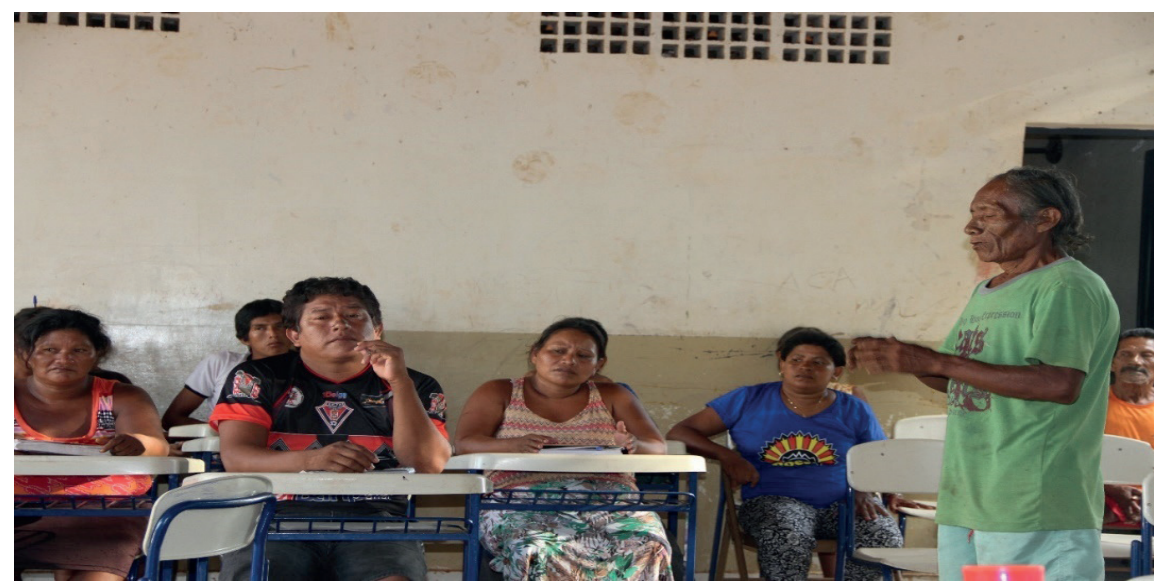

Fonte: Acervo pessoal do autor. 
Figura 3 - Direção, Coordenação Pedagógica, professores e lideranças da comunidade Apinajé em reunião para elaboração do PPP da Escola Indígena Tekator.

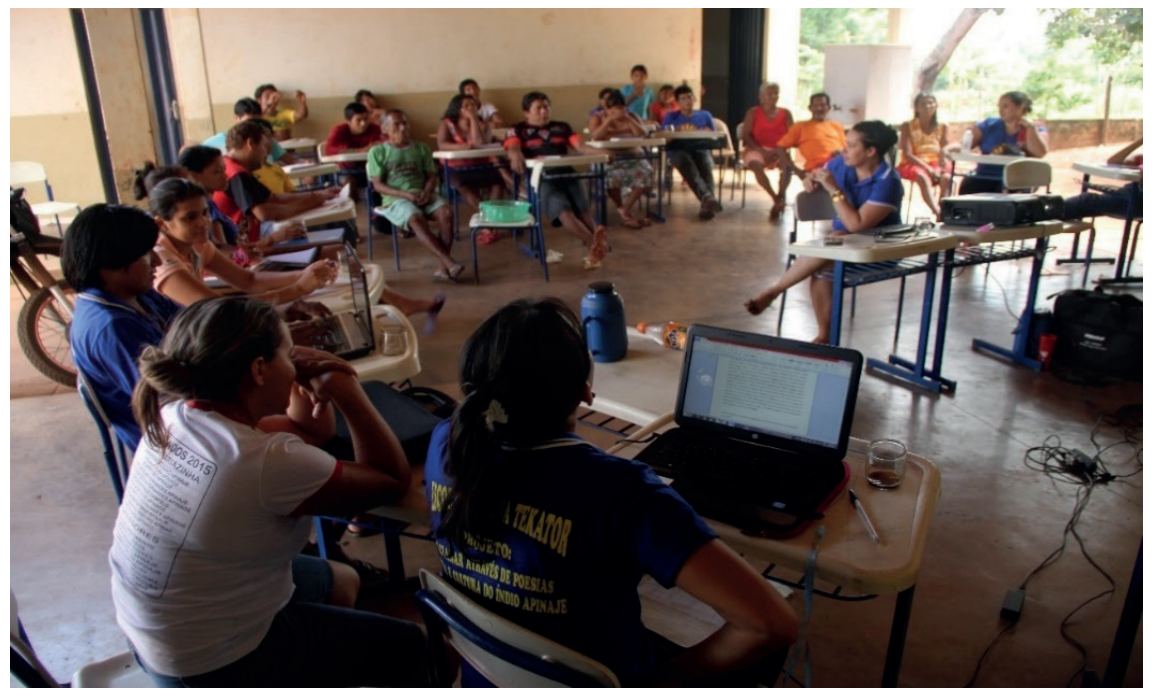

Fonte: Acervo pessoal do autor.

\section{REFERÊNCIAS}

CARELLI, Vincent. Mutirão guerreiro conquista demarcação Apinayé: mas os índios prometem lutar pela área do Gameleira. In: CEDI (Rio de Janeiro). ACONTECEU ESPECIAL: POVOS INDÍGENAS NO BRASIL 1985. $15^{\mathrm{a}}$ ed. Rio de Janeiro: CEDI, 1984-1985. p. 262-266. Disponível em: <https:// pt.scribd.com/doc/38257783/Aconteceu-Especial-numero-15-Povos-Indigenas-no-Brasil-1984>. Acesso em: 15 fev. 2016.

CLASTRES, Pierre. A sociedade contra o Estado: pesquisas de antropologia política. São Paulo: Cosac Naify, 2012. 288 p. Tradução de: Theo Santiago.

FERREIRA, Mariana Kawall Leal. A educação escolar indígena: um diagnóstico crítico da situação no Brasil. In: SILVA, Aracy Lopes da; FERREIRA, Mariana Kawall Leal (Orgas.). Antropologia, história e educação: a questão indígena e a escola. São Paulo: Global, 2001. p. 71-111.

GRUPIONI, Luís Donisete Benzi. Olhar longe, porque o futuro é longe: cultura, escola e professores indígenas no Brasil. 2008. 237 f. Tese (Doutorado) - Curso de Antropologia, da Faculdade de Filosofia, Letras e Ciências Humanas, Universidade de São Paulo, São Paulo, 2008. 
NIMUENDAJÚ, Curt. Os Apinayé. Belém: Museu Paraense Emílio Goeldi, 1983. $146 \mathrm{p}$.

SANTOS, Boaventura de Sousa; MENESES, Maria Paula. Epistemologias do Sul. Coimbra: Almedina, 2009.

SILVA, Paulo de Tássio Borges da. As relações de interculturalidade entre conhecimentos tradicionais na escola estadual indígena Kijetxawê Zabelê. Rio de Janeiro: Multifoco, 2014. 215 p.

SOTERO APINAYÉ, Cassiano; ALBUQUERQUE, Francisco Edviges. Contexto histórico da Educação Escolar Indígena Apinayé. In: ALBUQUERQUE, Francisco Edviges; ALMEIDA, Severina Alves de (Orgs.). Educação Escolar Indígena e Diversidade Cultural. Goiânia: América, 2012. p. 114-130. 
